\title{
Using different solid medium for blueberry soilless growth
}

\author{
Yanan Wang ${ }^{1,}$, Bowen Wang ${ }^{1, b}$, Zhaofang Chen ${ }^{1, c}$, Yuxin Wang ${ }^{1, d}$, Xun
}

\author{
Wang $^{2, \text { e, * }}$ \\ ${ }^{1}$ College of Horticulture, Sichuan Agricultural University, Chengdu, Sichuan, China \\ ${ }^{2}$ Institute of Pomology \& Olericulture, Sichuan Agricultural University, Chengdu, Sichuan, China \\ a894631252@qq.com, b464510296@qq.com, c1227426092@qq.com, d1050758436@qq.com \\ e, *Corresponding author: wangxun0104@hotmail.com
}

Keywords: solid medium, soilless culture, blueberry, growth and development

Abstract. In a pot experiment, we investigated the effect of different solid medium on blueberry 'Bluebelle' soilless culture. Solid medium included rice hull, wood chips, pine needle, plastic ball, perlite, slag, sawdust and coir. The results show that different treatments have different effect on different blueberry growth indicators. The medium mixing peat with perlite was the optimal medium for blueberry 'Bluebelle' growth.

\section{Introduction}

Blueberry (Vaccinium spp.) is known as cowberry and blue berries. It has high medical and economic value, and is hailed as "the king of berries" ${ }^{[1]}$. Blueberry is the new fruit species which has high economic value and broad prospects for development ${ }^{[2-6]}$. Blueberry prefers acidic soil, with the optimum $\mathrm{pH} 4.0 \sim 5.5$ and organic content $>5 \%{ }^{[7]}$. Soilless cultivation can solve the obvious shortcomings of traditional soil cultivation, but also has some advantages to adapt to modern agricultural production mode ${ }^{[8-9]}$. The physiological properties of blueberries determine their potential application in soilless culture. This study aimed at the solid medium selection for blueberry soilless growth development. We selected medium for blueberry cultivar 'Bluebelle', which is performed well in southern China. We compared six solid medium and evaluated the proper media via analyzing blueberry growth indicators. The research results are expected to provide practical guidance for the development of soilless culture of blueberries.

\section{Material and methods}

\section{Material}

Blueberry 'Bluebelle' was planted in pot at the experimental greenhouse of Sichuan Agricultural University (Chengdu campus).

Medium preparation

Six solid medium were mixed with peat by volume proportion $1: 1$, and sulfur $10 \mathrm{~g}$. The experiment treatments were set as follow: B1 (sawdust $\times$ peat); B2 (slag $\times$ peat); B3 (wood chips $\times$ peat); B4 (pine needle $\times$ peat); B5 (coir $\times$ peat); B6 (perlite $\times$ peat $)$.

Experiment design

Each solid medium was an experiment treatment, and 3 replications were set for each treatment. Plant height, crown weight, stem diameter and shoots length were measured once every 15 days. 


\section{Results and discussions}

The physical characters of medium

The solid media showed differences in bulk density, total porosity, and air water ratio (Table 1). The bulk density of slag was highest, up to $0.71 \mathrm{~g} / \mathrm{cm}^{-3}$, and the lowest is wood chips. The porosity of medium is important character, which reflects the absorbency of water and ability to hold air. Better porosity could hold more air and water and weaker porosity hold less air and water. The total porosity of coir is the best, the air porosity of wood chips is the best, and the water porosity of coir is the best. As for air water ratio, perlite is the best.

Table 1 The physical characters of different medium

\begin{tabular}{cccccc}
\hline substrate & $\begin{array}{c}\text { Bulk density/ } \\
\left(\mathrm{g} / \mathrm{cm}^{-3}\right)\end{array}$ & $\begin{array}{c}\text { Total porosity/ } \\
\%\end{array}$ & $\begin{array}{c}\text { Air porosity / } \\
\%\end{array}$ & $\begin{array}{c}\text { Water porosity / } \\
\%\end{array}$ & $\begin{array}{c}\text { Air water } \\
\text { ratio }\end{array}$ \\
\hline sawdust & 0.25 & 73.56 & 3.45 & 70.11 & 0.05 \\
slag & 0.71 & 60.92 & 22.99 & 37.93 & 0.61 \\
wood chips & 0.12 & 78.16 & 58.62 & 19.54 & 3.00 \\
pine needle & 0.14 & 78.16 & 51.72 & 26.44 & 1.96 \\
coir & 0.16 & 89.53 & 3.49 & 86.05 & 0.04 \\
perlite & 0.09 & 71.26 & 42.53 & 28.74 & 1.48 \\
\hline
\end{tabular}

Effect of different solid medium on blueberry plant height From the Figure 1, the plant height of 'Bluebelle' which grew in B2, B3, B4 and B5 is better. In the beginning the plant in B6 has the fastest growing. Then the plant in B4 grew fastest. Between the third measure and the fifth measure,the plant in B5 grew faster than others.

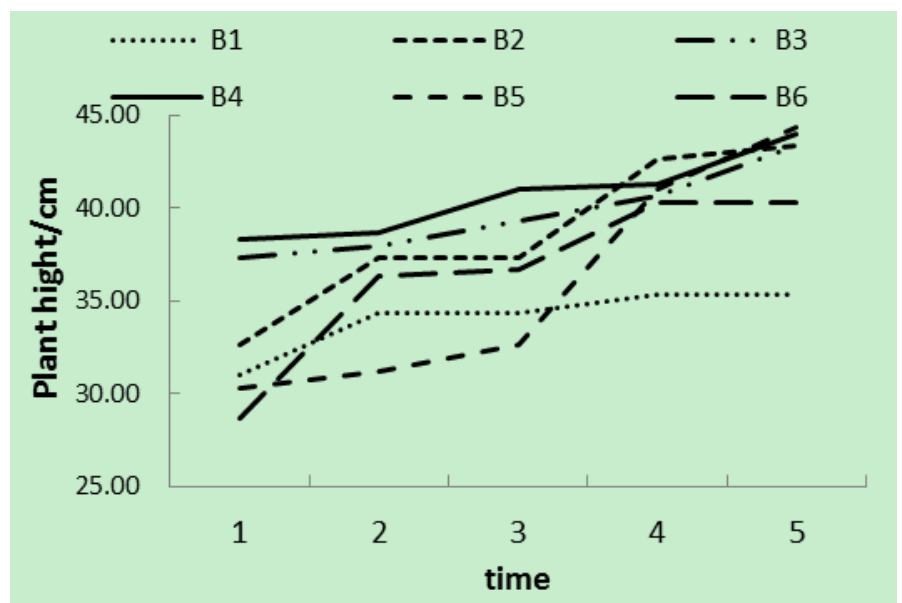

Fig. 1 Effect of different medium on 'Bluebelle' plant height

Effect of different medium on blueberry crown weight

The crown weight of 'Bluebelle' grew in B4 is best, but it is also the best in the beginning (Figure 2 ). As for the growth rate, in the beginning the plant in B4 has the fastest growing; in the pre metaphase the plant in B6 has the fastest growing; in the middle and late period the plant in B5 grew fastest; in the later period the plant in B3 grew faster than others. 


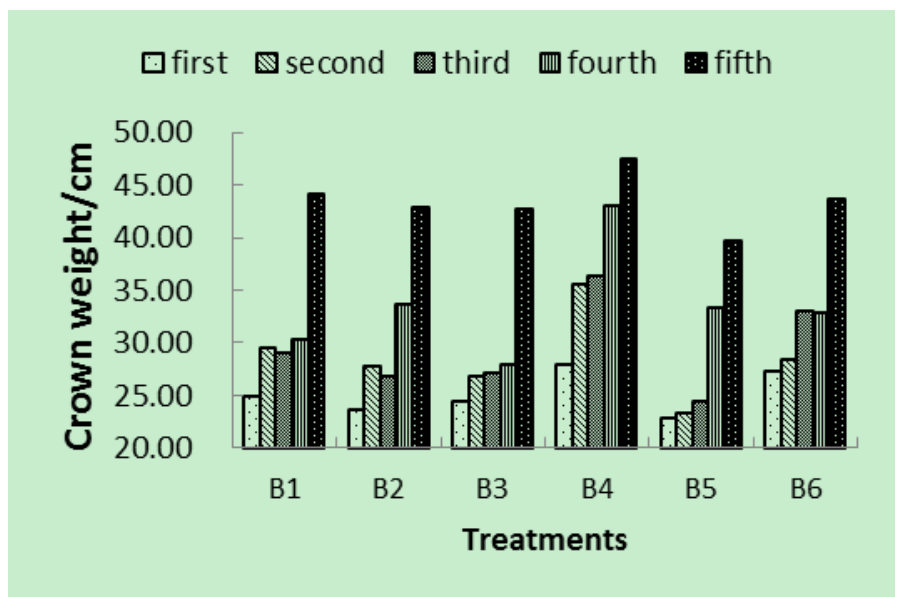

Fig. 2 Effect of different medium on 'Bluebelle' crown weight

Effect of different medium on blueberry stem diameter

The stem diameter of 'Bluebelle' which grew in B6 is best and B1 is also great (Figure 3). From the point of view of growth rate, in the beginning the plant in B4 has the fastest growing; in the middle and later period, the plant in B6 grew fastest.

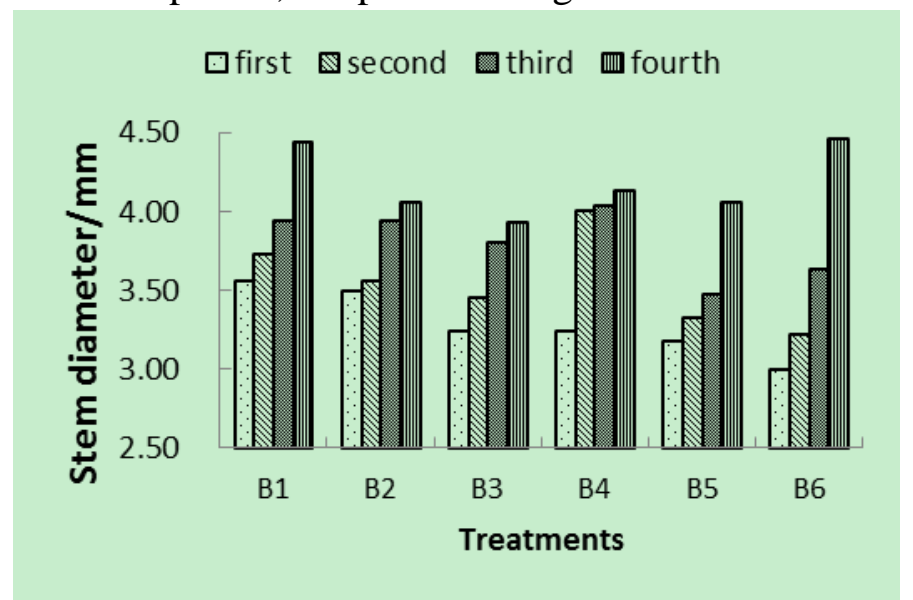

Fig. 3 Effect of different medium on 'Bluebelle' stem diameter

Effect of different medium on blueberry shoots length

The shoots length of 'Bluebelle' which grew in B1 is best (Figure 4). In the beginning the plant in B6 has the fastest growing, but the plant in B1 grew fastest in the later periods.

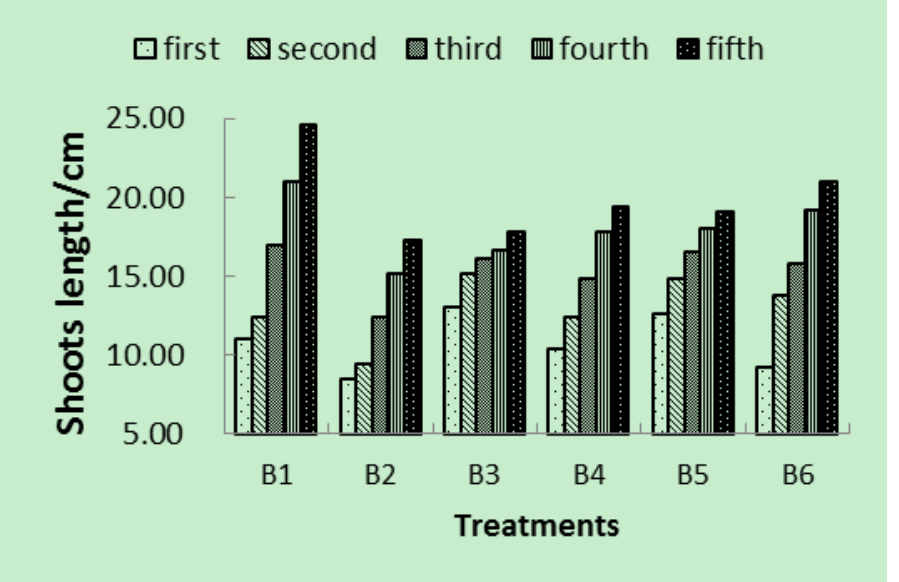

Fig. 4 Effect of different medium on 'Bluebelle' shoots length 


\section{Conclusion}

From the results, 'Bluebelle' plant height showed good performance in B5 treatment, crown weight showed good performance in B4 treatments, stem diameter showed good performance in B6, and shoots length showed good performance in B1. The experiment results showed that soilless potted blueberry plants without using soil reduced the disease, insects and grass trouble. The solid medium of small bulk density is easy to operate and it is helpful to reduce transportation cost $^{[10]}$. All medium were at the range of ideal total porosity $(60 \%-90 \%)^{[11]}$. Being mixed with peat, these media were improved physical characters. The root environment of blueberries can be also improved.

Our research could provide reference for future blueberry soilless culture. It is possible to obtain good economic, ecological and social benefits if applying the results of this experiment to production practice.

\section{References}

[1] Wang X., Wang P.Y., Wang S., et al. Status and prospect of blueberry in china. Agricultural Modernization, 29 (2): 250-253(2008).

[2] Shi L.C. Technology of blueberry in pot in hebei province. Hebei Fruit Tree, (2): 37-38(2015).

[3] Joshi, S., Howell, A. B., DSouza, D.H.. Blueberry proanthocyanidins against human norovirus surrogates in model foods and under simulated gastric conditions. Food Microbiology, 63:263(2016).

[4] Poulose S.M., Kelly M.E., Bielinski D.F., et al. Anthocyanin-rich blueberry diets enhance protection of critical brain regions exposed to acute levels of ${ }^{56} \mathrm{Fe}$ cosmic radiation. The FASEB Journal, 30(Supplement 1):679(2016)

[5] Rodriguez-Mateos A., Feliciano R.P., Cifuentes-Gomez T., et al. Bioavailability of wild blueberry (poly) phenols at different levels of intake. Journal of Berry Research, 6 (2):137-148(2016).

[6] Heijden, R.A.V.D., Morrison, M.C., Sheedfar, F., et al. Effects of anthocyanin and flavanol compounds on lipid metabolism and adipose tissue associated systemic inflammation in diet-induced obesity. Mediators of Inflammation, (8):1-10(2016).

[7] Wang L., Pan J., Wan Z.B.. Research and development of blueberry cultivation substrate and special nutrient substrate. Huangshan University, 13 (05): 60-62(2011).

[8] Wang X.L., Wang Z.X., Zhang W.H.. Research progress of strawberry soilless culture and nutrient solution. Jiangsu Academy of Agricultural Sciences, 23 (06): 83-86(2017).

[9] Zha M.. Organic eco-soilless culture of vegetables, Friends of Farmers, (18): 73-74(2016).

[10] Wang L.F., Pan B., Qi X.X., et al. Optimization screening of urethane cultivation substance for bovine ear. Northern Horticulture, (03): 76-80(2017).

[11] Song ZG. Study on soilless culture substrate of tomato with different crop stalks. Chinese Academy of Agricultural Sciences, (2013). 